\title{
АНАЛИЗ КОНКУРЕНТНЫХ ВОЗМОЖНОСТЕЙ ШВЕДСКОЙ КРОНЫ В МИРОВОЙ ВАЛЮТНО-ФИНАНСОВОЙ СИСТЕМЕ *
}

\author{
(c) 2020 Алексеев Петр Викторович \\ кандидат экономических наук, ведущий научный сотрудник \\ Институт мировой экономики и международных финансов \\ Финансовый университет при Правительстве Российской Федерации, Россия, Москва \\ E-mail: palekseev@fa.ru
}

Сегодня шведская крона является одной из наименее стабильных ведущих валют в мировой валютно-финансовой системе, подверженной устойчивой девальвации, что обусловлено постепенным ухудшением социально-экономического положения Швеции в последние десятилетия. В статье показано, что дополнительным фактором обесценения шведской кроны может стать пандемия коронавируса. В этой связи прогнозируется дальнейшее ослабление конкурентных позиций шведской кроны в мировой валютно-финансовой системе (МВФС) в результате действия ряда выявленных субъективных и объективных факторов.

Ключевые слова: мировая валютно-финансовая система, Швеция, шведская крона, конкуренция валют, таргетирование инфляции.

Официальная валюта Швеции - шведская крона (равна 100 эре) (международный код валюты - SEK) - была введена в обращение в 1873 году в результате создания Скандинавского валютного союза (в составе Швеции, Дании, Норвегии), существовавшего до 1914 г., заменив прежнюю денежную единицу - риксдалер.

По данным МВФ, с 1992 г. применяется режим свободно плавающего валютного курса шведской кроны в рамках реализуемой Риксбанком (центральным банком Швеции) стратегии таргетирования инфляции [1]. В феврале 1961 г. Швеция официально присоединилась к ст. VIII устава МВФ, отменив ограничения по текущим операциям платежного баланса. Вместе с тем, по состоянию на 31 декабря 2017 г., действует ряд валютных ограничений на следующие виды финансовых операций:

- операции с долевыми и долговыми ценными бумагами;

- операции с инструментами денежного рынка (депозитные сертификаты, векселя и др. со сроком не более 1 года) и деривативами;

- финансовые кредиты;

- прямые иностранные инвестиции;

- операции с недвижимостью [1].

Швеция является членом Европейского союза, но не участвует в функционирующем с 1999 г. европейском Экономическом и валютном союзе.
По итогам проведенного в 2003 г. референдума, более половины населения Швеции не поддержали замену кроны на евро.

По сравнению с другими ведущими валютами, шведская крона менее стабильна, находясь в рейтинге устойчивости валют на девятом месте [2]. Это определяет её сравнительно скромное положение в МВФС как валюты цены контрактов, международного платежного средства, инструмента операций на мировом валютном, долговом и кредитном рынке, валюты международных резервов. Конкурентные позиции кроны в МВФС в 2007-2019 гг. ослабли (её доля в общем объеме операций мирового валютного рынка сократилась с 3\% в 2007 г. до 2\% в 2019 г.) (таблица 1). При этом увеличивается значение двух основных валютных пар при совершении операций с кроной - «USD/SEK» и «EUR/SEK». Среднедневной оборот по первой валютной паре возрос с 57 млрд. долл. в 2007 г. до 86 млрд. долл. в 2019 г., по второй валютной паре - с 24 до 36 млрд. долл. [3]. В относительном выражении, доля первой валютной пары в среднедневном объеме валютных операций в шведских кронах в указанный период возросла 63,3\% до 64,1\%, доля второй пары - с 26,7\% до 26,9\% [3].

Основным фактором ослабления конкурентных позиций шведской кроны является устойчивая тенденция её девальвации к ведущим

\footnotetext{
* Статья подготовлена по результатам исследований, выполненных за счет бюджетных средств по государственному заданию Финуниверситету.
} 
Таблица 1. Среднедневной объем валютных операций в шведских кронах, в млрд. долл. и \% общего объема операций мирового валютного рынка в 2001-2019 гг.

\begin{tabular}{|c|c|c|c|c|c|c|c|c|c|c|c|c|c|c|}
\hline & \multicolumn{2}{|c|}{2001} & \multicolumn{2}{|c|}{2004} & \multicolumn{2}{|c|}{2007} & \multicolumn{2}{|c|}{2010} & \multicolumn{2}{|c|}{2013} & \multicolumn{2}{|c|}{2016} & \multicolumn{2}{|c|}{2019} \\
\hline & Объем & $\%$ & Объем & $\%$ & Объем & $\%$ & Объем & $\%$ & Объем & $\%$ & Объем & $\%$ & Объем & $\%$ \\
\hline SEK & 31 & 2 & 42 & 2 & 90 & 3 & 87 & 2 & 94 & 2 & 112 & 2 & 134 & 2 \\
\hline \multicolumn{15}{|c|}{ Справочно: } \\
\hline USD & 1114 & 90 & 1702 & 88 & 2845 & 86 & 3371 & 85 & 4662 & 87 & 4437 & 88 & 5824 & 88 \\
\hline EUR & 470 & 38 & 724 & 37 & 1231 & 37 & 1551 & 39 & 1790 & 33 & 1590 & 31 & 2129 & 32 \\
\hline
\end{tabular}

Источник: URL: https://www.bis.org/statistics/d11_3.pdf. Дата обращения: 15.06.2020.

мировым валютам (доллару и евро), главным образом вследствие использования Риксбанком режима свободного плавания курса кроны, замедления темпов роста ВВП (с 4,9\% в 2000 г. до 0,9\% в 2019 г.), а также ряда негативных тенденций и явлений, в том числе:

- сокращение потенциала трудовых ресурсов страны под влиянием негативных демографических тенденций, включая снижение коэффициента рождаемости, рост доли жителей возрастом свыше 65 лет в общей численности населения, снижение с 2016 г. притока мигрантов из развивающихся стран (Сирия, Ирак, Афганистан и др.), которые в последние годы во многом обеспечивали прирост объема ВВП страны (таблица 2);

- тенденция к снижению сальдо текущих операций платежного баланса с 29,1 млрд. долл. в 2010 г. до 15,2 млрд. долл. в 2019 г. (таблица 3);

- торговый конфликт между США и ЕС в 2018 г. *, а также пандемия коронавируса в 20192020 гг.
Пандемия коронавируса оказала сильное негативное влияние на население и экономику Швеции **. По мнению министра финансов Швеции М. Андерссен, высказанному в мае 2020 г, в результате пандемии ВВП страны снизится, безработица вырастет, а в государственных финансах Швеции будет большой дефицит [4]. Согласно прогнозу Еврокомиссии, сделанному в мае 2020 г., падение ВВП Швеции составит в 2020 г. 6,1\%, а уровень безработицы вырастет до 9,7\% [4]. Это существенно ослабит конкурентные позиции шведской кроны в МВФС.

Как видно из рисунков 1 и 2, несмотря на колебания, шведская крона обесценилась с 4 крон за 1 долл. на 1 января 1975 г. до 9,22 крон за 1 долл. на 11 июня 2020 г. (на 159\%) [5] и с 9,5 евро 1 января 1999 г. до 11,51 крон на 12 июня 2020 г. (на 21\%) [6].

В настоящее время проводимая Риксбанком монетарная политика, сопровождаемая девальвацией кроны, нацелена на поддержание конкурентоспособности шведского экспорта и

Таблица 2. Основные демографические показатели Швеции в 2011-2018 гг.

\begin{tabular}{|l|c|c|c|c|c|c|c|c|}
\hline & 2011 & 2012 & 2013 & 2014 & 2015 & 2016 & 2017 & 2018 \\
\hline $\begin{array}{l}\text { Численность населения, млн. чел. } \\
\text { (на 1 января периода) }\end{array}$ & 9,4 & 9,5 & 9,6 & 9,6 & 9,7 & 9,9 & 10,0 & 10,1 \\
\hline Коэффициент рождаемости & 1,9 & 1,91 & 1,89 & 1,88 & 1,85 & 1,85 & 1,78 & 1,76 \\
\hline Коэффициент смертности & 9,5 & 9,7 & 9,4 & 9,2 & 9,3 & 9,2 & 9,1 & 9,1 \\
\hline Иммиграция, чел. & 96467 & 103059 & 115845 & 126966 & 134240 & 163005 & 144489 & 132602 \\
\hline Эмиграция, чел. & 12660 & 13845 & 13893 & 15486 & 16305 & 18082 & 16973 & 19141 \\
\hline Сальдо миграции, чел. & 83807 & 89214 & 101952 & 111480 & 117935 & 144923 & 127516 & 113461 \\
\hline $\begin{array}{l}\text { Доля населения возрастом свыше 65 } \\
\text { лет в общей численности населения, \% }\end{array}$ & 18,5 & 18,8 & 19,1 & 19,4 & 19,6 & 19,8 & 19,8 & 19,8 \\
\hline
\end{tabular}

Источник: URL: https://ec.europa.eu/eurostat/data/database. Дата обращения: 15.06.2020.

\footnotetext{
* В июне 2008 г. США в одностороннем порядке повысили импортные пошлины на европейскую сталь (до 25\%) и алюминий (до 10\%). В ответ ЕС увеличил пошлины на импорт ряда потребительских товаров из США. Это вызвало напряженность в торговых отношениях США и ЕС.

** По состоянию на 15 июня 2020 г., в Швеции заражено коронавирусом 51614 человек, 4971 человек выздоровели, 4874 умерли (URL: coronavirus-monitoring.ru. Дата обращения: 15.06.2020).
} 
Таблица 3. Основные макроэкономические показатели Швеции в 2000-2019 гг.

\begin{tabular}{|l|c|c|c|c|c|c|c|c|c|}
\hline \multicolumn{1}{|c|}{ Показатели } & 2000 & 2005 & 2010 & 2014 & 2015 & 2016 & 2017 & 2018 & 2019 \\
\hline $\begin{array}{l}\text { Темп прироста реального } \\
\text { ВВП, \% }\end{array}$ & 4,9 & 2,9 & 6,2 & 2,7 & 4,4 & 2,4 & 2,4 & 2,3 & 0,9 \\
\hline $\begin{array}{l}\text { ВВП на душу населения в } \\
\text { постоянных ценах, долл. }\end{array}$ & 36877,3 & 41206,2 & 43458,5 & 44649,1 & 46132,4 & 46564,3 & 47097,9 & 47674,5 & 47691,9 \\
\hline $\begin{array}{l}\text { Доля ВВП по ППС в мировом } \\
\text { ВВП, \% }\end{array}$ & 0,5 & 0,5 & 0,4 & 0,4 & 0,4 & 0,4 & 0,4 & 0,4 & 0,4 \\
\hline Валовое накопление, \% ВВП & 23,2 & 22,5 & 23,2 & 23,7 & 24,4 & 24,7 & 25,8 & 26,9 & 26,2 \\
\hline $\begin{array}{l}\text { Темпы инфляции по индексу } \\
\text { потребительских цен, \% }\end{array}$ & 1,5 & 1,1 & 1,8 & 0,3 & 0,9 & 1,4 & 1,8 & 2,2 & 1,6 \\
\hline $\begin{array}{l}\text { Темп прироста импорта } \\
\text { товаров и услуг, \% }\end{array}$ & 13,0 & 8,4 & 11,8 & 6,7 & 5,0 & 4,2 & 6,3 & 3,7 & 2,0 \\
\hline $\begin{array}{l}\text { Темп прироста экспорта } \\
\text { товаров и услуг, \% }\end{array}$ & 12,9 & 7,1 & 11,1 & 4,6 & 5,8 & 2,7 & 3,1 & 2,7 & 4,0 \\
\hline Уровень безработицы, \% & 6,3 & 7,6 & 8,6 & 7,9 & 7,4 & 7,0 & 6,7 & 6,3 & 6,5 \\
\hline $\begin{array}{l}\text { Сальдо государственного } \\
\text { бюджета, \% ВВП }\end{array}$ & 3,2 & 1,8 & $-0,03$ & $-1,54$ & 0,16 & 1,1 & 1,5 & 0,9 & 0,4 \\
\hline $\begin{array}{l}\text { Сальдо текущего счета пла- } \\
\text { тежного баланса, млрд. долл. }\end{array}$ & 10,3 & 23,5 & 29,1 & 26,1 & 20,7 & 19,4 & 15,1 & 9,6 & 15,2 \\
\hline $\begin{array}{l}\text { Сальдо текущего счета пла- } \\
\text { тежного баланса, \% ВвП }\end{array}$ & 3,9 & 6,0 & 5,9 & 4,5 & 4,1 & 3,8 & 2,8 & 1,7 & 2,9 \\
\hline
\end{tabular}

Источник: IMF World Economic Outlook. URL: https://www.imf.org/external/pubs/ft/weo/2019/ 02/weodata/index.aspx. Дата обращения: 15.06.2020.

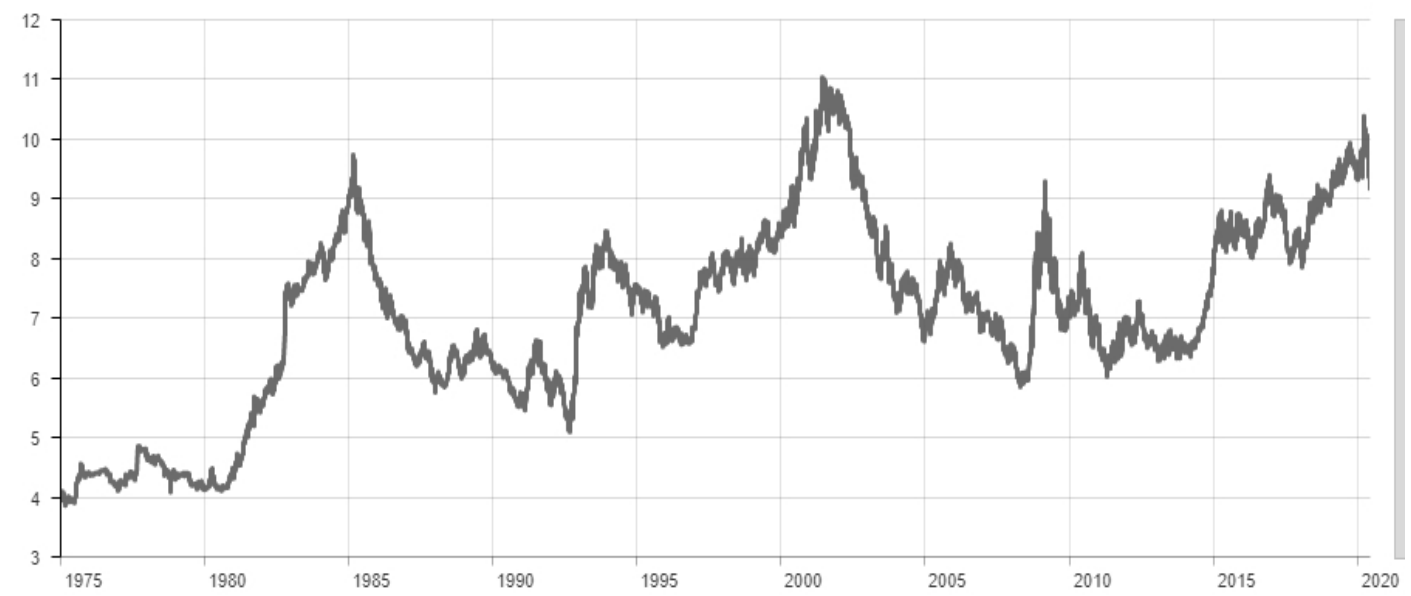

Puc. 1. Динамика курса шведской кроны к доллару США в 1975-2020 гг. (крон за 1 доллар) Источник: [5] 


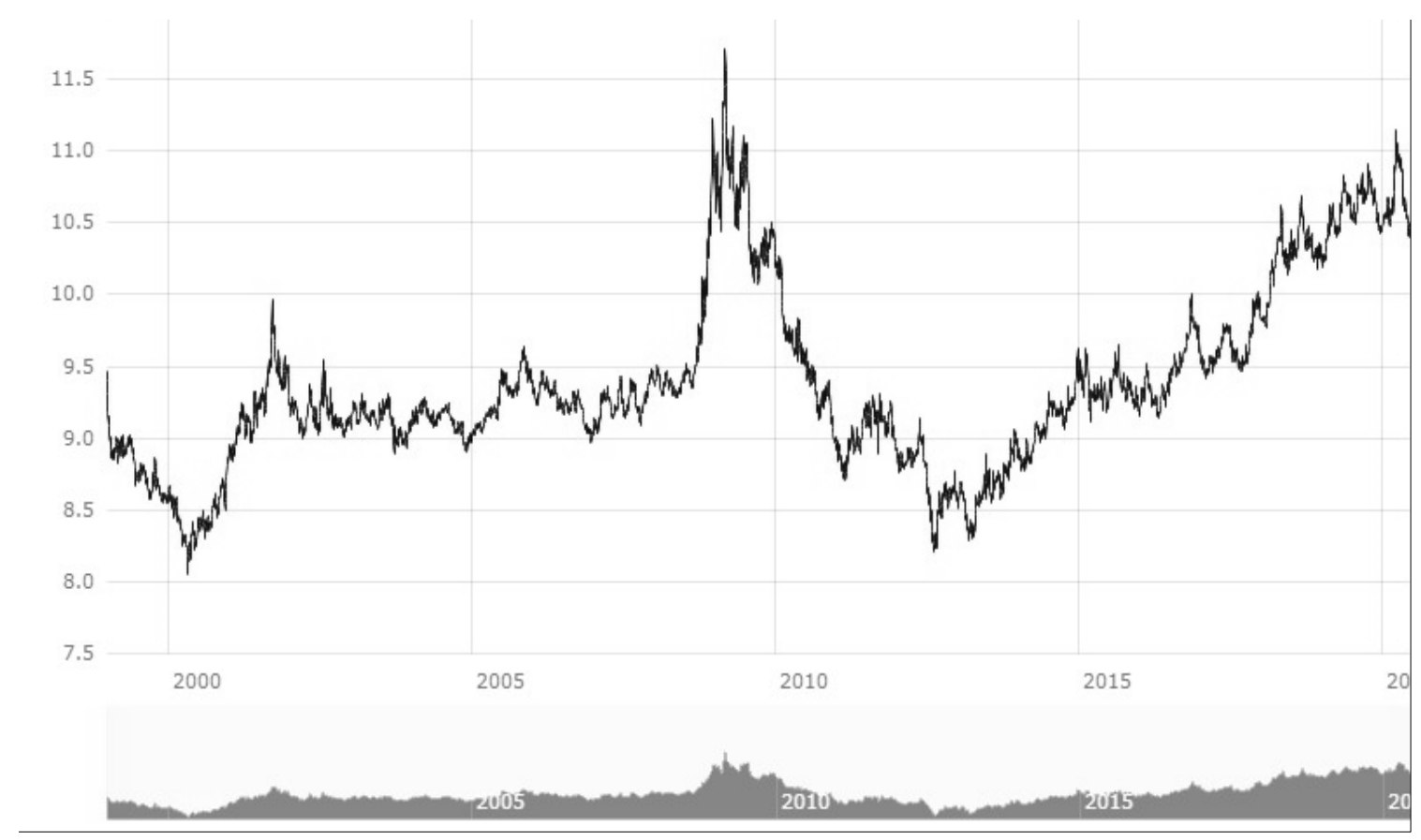

Рисунок 2. Динамика курса шведской кроны к евро в 1999-2020 гг. (крон за 1 евро) Источник: [6]

обеспечение экономического роста. Такая политика вызывает серьезную озабоченность у экспертов. По мнению представителя шведского банка «Nordea» Х. Унелла, «снижение стоимости кроны напоминает ситуацию в странах после совершившихся государственных переворотов» [7]. Х.Унелл считает, что причиной обесценения кроны является политика Риксбанка, который поддерживает процентные ставки на крайне низком уровне *. В свою очередь, глава Риксбанка С.Ингвес мотивирует политику низких процентных ставок необходимостью содействовать экономическому росту в стране [7].
Резюмируя вышесказанное, следует отметить, что в настоящее время наблюдается тенденция ухудшения позиций шведской кроны в МВФС, которое вызвано главным образом политикой конкурентной девальвации кроны, проводимой Риксбанком. Пандемия коронавируса также будет способствовать ослаблению конкурентных позиций кроны в МВФС. В этих условиях, вполне вероятно, что сфера использования шведской кроны в международном обороте будет сужаться с перспективой вытеснения ее из МВФС валютами других стран с более конкурентоспособной экономикой.

\section{Библиографический список}

1. Annual Report on Exchange Arrangements and Exchange Restrictions 2018. C. 7. URL: https://www.imf.org/ en/Publications/Annual-Report-on-Exchange-Arrangements-and-Exchange-Restrictions/Issues/2019/04/24/ Annual-Report-on-Exchange-Arrangements-and-Exchange-Restrictions-2018-46162. Дата обращения: 15.06.2020.

2. Рейтинг информационно-аналитического издания «Банки сегодня» «ТОП-10 самых стабильных валют в мире». https://bankstoday.net/last-articles/top-10-samyh-stabilnyh-valyut-v-mire. Дата обращения: 15.06.2020.

3. Triennial Central Bank Survey. Foreign Exchange Turnover in April 2019. P.11. Basel, BIS, 16 September 2019. URL: https://www.bis.org/statistics/rpfx19.htm. Дата обращения: 15.06.2020.

4. Минфин Швеции: размер падения ВВП из-за кризиса зависит от структуры экономик стран. URL: https:// tass.ru/ekonomika/8567425. Дата обращения: 15.06.2020.

\footnotetext{
* Ключевая процентная ставка Риксбанка постепенно снижается в последние годы (с 4,25\% на 1 января 2000 г. до 0,20\% на 15 июня 2020 г.) (URL: https://www.riksbank.se/en-gb/statistics/search-interest-exchange-rates. Дата обращения: 15.06.2020).
} 
5. URL: https://www.bankofengland.co.uk/boeapps/database/fromshowcolumns.asp? Travel=NIxAZxRSxSUx\&From Series $=1 \&$ ToSeries $=50 \& D A T=R N G \& F D=1 \& F M=J a n \& F Y=2007 \& T D=31 \& T M=$ Dec $\&$ TY=2010 \&FNY= \&CSVF=TT \& html.x=135\&html.y=40\&C=ECY \&Filter=N. Дата обращения: 15.06.2020.

6. URL: https://www.ecb.europa.eu/stats/policy_and_exchange_rates/euro_reference_exchange_rates/html/ eurofxref-graph-sek.en.html. Дата обращения: 15.06.2020.

7. Free fall of Swedish Krona comparable to a country suffering a coup d'etat. https://www.sott.net/article/411538Free-fall-of-Swedish-Krona-comparable-to-a-country-suffering-a-coup-d-etat. Дата обращения: 15.06.2020. 